\title{
Stolen report alleging discrimination and favouritism in NIH office raises furore
}

\begin{abstract}
Washington. An independent report supporting allegations that senior managers in the procurement office at the US National Institutes of Health (NIH) have systematically discriminated against African-Americans and have operated a 'social network' in which sexual favours are exchanged for career advancement has become the focus of a campaign by two civil rights organizations to improve conditions for blacks at NIH. Their anger has been fuelled by the theft of the report from the consultant's office on the morning after it was submitted to NIH last autumn - including the codes intended to provide anonymity for witnesses who supplied the consultant with evidence of misconduct.
\end{abstract}

The report was prepared by Benjamin Alexander, a former senior US government official and a former university president who was trained as a chemist. Alexander was hired to investigate the validity of complaints of discrimination and favouritism dating from 1987 against the office of acquisition management within the NIH director's office. In the course of the five-month study, Alexander interviewed several dozen witnesses who, under the promise of anonymity, described an "ole boy network" of preferential hiring and promotion, a pattern of unfair performance ratings and the use of inappropriate educational requirements for available jobs.

Those conclusions were reached on the basis of answers from a control group of employees in the office that matched the administrative levels of those accused of acting improperly and the racial composition of those making the allegations. Alexander found that the control group shared the views of the complainants and disagreed with those supporting the managers in 18 out of 20 areas.

On 19 September, the day after Alexander submitted the report to Diane Armstrong, director of NIH's Office of Equal Opportunity, thieves broke into the offices of Alexander's company, Drew Dawn \& Associates of Silver Spring, Maryland, and stole the report along with the codes. The local police found no incriminating evidence at the scene and they believe that the theft, which did not involve office equipment and other items of value, was done by professionals.

Last week, the Montgomery County (Maryland) chapter of the National Association for the Advancement of Colored People (NAACP), tired of waiting for the police to solve the case and for NIH to comment on the report, held a press conference to express its outrage at the events of the past seven months and to demand that the lives of those affected "be made whole". The group, along with the NIH chapter of Blacks in Government (BIG), wants the Federal Bureau of Investigations to help solve the break-in and wants NIH to act promptly to resolve the complaints of discrimination and to punish those responsible.

The civil-rights groups are particularly upset with NIH's response to the news that the confidentiality of those who provided information to Alexander had been breached. Within 24 hours, NIH security police were given the list of names and told to call each person to tell them of the theft. NIH officials say only that the witnesses were notified "in the most expeditious way possible"; members of BIG insist that a telephone tree was created in which one person was told to call several others. In any case, the names of those who had provided confidential information were soon common knowledge within the relevant offices at NIH.

NIH says that criticism of its response to both the report and the theft is unfair. Armstrong says that the report has convinced NIH officials that "there are some serious problems in the office of acquisitions management" and that, as a result, NIH has hired another consultant "to advise us if there is information that we can act upon". The Alexander report was revised four times before it was acceptable, according to Armstrong, who said that the final version "does not contain any sworn statements or evidence that could provide the basis for specific actions against anyone". In the interim, she adds, NIH has scheduled training on sexual discrimination and cultural awareness for the entire division. As for the breakin, Armstrong says that the report "was not our property" at the time it was stolen, so it is not clear what role NIH should play in an investigation.

The civil rights groups say that NIH is not doing enough. "We're not happy with what is going on", says Vincent Thomas, president of the BIG chapter at NIH. "We've said all along that the key is managerial accountability, and until NIH is willing to punish people for their behavior, nothing is going to change."

Jeffrey Mervis

\section{Russia gets first batch of emergency grants}

Moscow. With $100 \$ 500$ grants already on their way to scientists working in Russia, the International Science Foundation (ISF) has taken the first step towards meeting its goal of helping to preserve research in the former Soviet Union.

The foundation, created last autumn by US financier George Soros, expects to make a second set of emergency grants to as many as 20,000 scientists after the 31 May deadline for applications. ISF officials are selecting researchers on the basis of the quality and quantity of their published output (see Nature 362, 95; 1993), although only a portion of the 35,000 who are eligible are applying for money to keep their laboratories going. Scientists may also be reimbursed for the cost of attending international conferences.

Segments of the Russian press have criticized the ISF and point to the modest size of ISF grants as evidence that the foundation is trying to 'buy' Russian scientific brain power at a fraction of its real value. Others are grateful for the additional money but believe that the ISF should work more closely with government agencies. Aurab Yakobashvili, deputy minister of science, says that the lack of such coordination makes it more difficult for the government to plan for the future of Russian science. Still others have raised questions about the criteria adopted by the ISF for judging applicants.

Alex Goldfarb, executive director of the
ISF and formerly a biochemist at the Engelhardt Institute in Moscow, sees the gap between the number of applicants and the number of eligible scientists as a sign that many of his colleagues have left the country for greener pastures in the West or have taken up another occupation. The imminent loss of perhaps a third of the cream of Russian science, he says, demonstrates the importance of taking rapid action, by whatever means available, to help those still willing and able to do science.

In addition to the emergency grants to individuals and small teams, the foundation has also given $\$ 500,000$ to the Komarov Botanical Institute in St Petersburg for the preservation of one of the world's largest herbaria. Some $\$ 80,000$ was awarded to a popular science magazine Chemistry and Life and $\$ 4,000$ was given to a special high school in Moscow that maintains high standards for teaching physics and mathematics. Soros has promised to spend a total of $\$ 100$ million on strengthening science in the former Soviet Union.

Boris Saltykov, the minister of science, believes that Soros's commitment has spurred Western governments into doing more than they would have done otherwise. "I can't prove it", he says, "but I believe that the activities of George Soros helped to push the Clinton administration into taking effective steps to assist Russian science".

Vladimir Pokrovsky 